\title{
ENVELHECIMENTO, VELHICE E SAÚDE: TRANSFORMANDO O INVISÍVEL EM VISÍVEL
}

Ageing, health and oldness: changing the invisible into visible

Parar no meio do turbilhão

Olhar para além da estrela

Ouvir aqueles que não têm voz

Consoante

Transformar o invisível

Em visível

Bibiana Graeff

${ }^{1}$ Escola de Artes, Ciências e Humanidades, Universidade de São Paulo. São Paulo/SP, Brasil.

Correspondência: Bibiana Graeff. E-mail: bibiana.graeff@usp.br.

Recebido em: 31/05/2014. 
Velhice não é sinônimo de doença, nem, aliás, de fragilidade. Existem distintas realidades vividas em idade mais avançada. Para algumas pessoas, pode significar inclusive a etapa do ciclo vital vivida com mais saúde, entendida em sua ampla concepção que, segundo a Organização Mundial da Saúde, inclui aspectos físicos, sociais e mentais. Recordo-me aqui, apenas para ilustrar, de alguns relatos de mulheres brasileiras, de diferentes situações socioeconômicas e culturais, de que foi apenas na velhice que vieram a encontrar um verdadeiro bem-estar, liberdade para fazer o que bem entendiam, para falar o que pensavam. Uma delas, de classe média, encontrou o tempo livre da aposentadoria e da independência dos filhos para dedicar-se a novas atividades prazerosas e para viajar. A outra, viúva, e ainda tendo a necessidade de trabalhar, contava-me a felicidade de, pela primeira vez na vida, poder estudar e realizar atividades, outrora impensáveis em sua realidade, em um centro de convivência. Isso não é saúde?

Contudo, não há dúvidas de que a velhice, vista como última etapa do ciclo vital, representa, de certo modo, maior proximidade com a morte. Também não se nega que, estatisticamente, e em termos gerais, verifica-se maior comorbidade em pessoas de idade mais avançada. E que o processo de envelhecimento implica declínios de funções biológicas, mesmo que em ritmos diferentes e atingindo diferentemente cada pessoa. E que talvez, por todos esses motivos, as preocupações com saúde sejam tão presentes para as pessoas idosas. Com efeito, de modo geral, como demonstram alguns estudos, a saúde passa a representar, na percepção do sujeito com mais idade, uma das primeiras preocupações, algo peculiar dessa fase da vida.

Assim, se admitimos que a velhice encerra uma peculiar relação com questões de saúde, seja em aspectos práticos, seja em aspectos subjetivos, resta saber em que e como essa especificidade se manifesta (ou deveria se manifestar) em termos jurídicos. O respeito à igualdade, para a população idosa, em aspectos relacionados ao direito à saúde, deve passar tanto pelo combate a algumas formas de discriminação (vide os aumentos abusivos em planos de saúde em função da idade) quanto pela adoção de medidas promocionais de inclusão (e aí entram ações afirmativas necessárias para a busca de igualdade substantiva, material).

Para a promoção de saúde, pensando-se em termos demográficos, por exemplo, o envelhecimento populacional implica uma nova cultura do cuidado, que deve somar-se às tradicionais dimensões da prevenção e do tratamento, como preconizado pela Declaração do Rio de Janeiro ${ }^{1}$, fruto de evento promovido pelo Centro Internacional de Longevidade do Brasil e pela World Demographic Association no ano de 2013. Os cuidados necessários para a realização de atividades básicas ou instrumentais da vida diária, fundamentais para um número crescente da população brasileira, não poderão ser vistos como um privilégio daqueles que podem pagar por isso, mas devem ser concebidos e tratados como direito fundamental universal, por sua íntima relação com o direito à saúde e com o direito personalíssimo ao envelhecimento em dignidade. Assim, a responsabilidade pela garantia de acesso aos cuidados 
para aqueles que deles necessitarem não recairá exclusivamente sobre o indivíduo prevenido ou sobre as famílias bem-afortunadas: trata-se de uma questão de cunho social, e como tal deve ser também assumida pela sociedade e pelo Estado. Seriam as políticas públicas relacionadas a esses cuidados para as atividades da vida diária (formação de cuidadores, programas de acompanhantes, centros-dias, seguros...) de responsabilidade da saúde, da previdência, da assistência social? Hoje, no Brasil, os três pilares da seguridade social se envolvem, em certa medida, dependendo do local, com políticas relacionadas ao cuidado. Como coordenar essas políticas?

Há muito a ser pensado sobre as relações entre saúde e velhice, e as novas políticas públicas necessárias num contexto de envelhecimento populacional. $\mathrm{O}$ objetivo da presente seção temática foi o de abordar algumas dessas questões, longe de poder explorar a diversidade de matérias possivelmente relacionadas ao assunto geral proposto. Assim, dois dos textos que compõem a tríade de artigos aqui apresentada trazem uma análise mais genérica e voltada ao contexto brasileiro, enquanto o terceiro refere-se a um tema mais específico e ilustrado a partir do direito francês. Os dois primeiros trabalhos tratam de como, por que e o que priorizar em se tratando de atendimento de saúde à população idosa, diante das limitações financeiras e materiais hoje existentes no Estado brasileiro. O primeiro deles considera a necessidade de se pensar em um mínimo existencial em matéria de saúde para $o$ idoso. Parte da afirmação dos cuidados de saúde como direitos fundamentais, consagrados tanto em tratados internacionais quanto no direito interno. Questiona se haveria um reconhecimento normativo da peculiaridade dos "cuidados de saúde a idosos". Os textos das convenções internacionais que se referem ao direito à saúde citados realmente não chegam a, explicitamente, mencionar qualquer peculiaridade relacionada à saúde do idoso. Porém, ao se observar o pouco que existe de afirmação de "direitos dos idosos" no Direito Internacional, percebe-se que, no sistema interamericano de direitos humanos, a saúde é expressamente citada, posto que:

Toda pessoa tem direito à proteção especial na velhice. Nesse sentido, os Estados Partes comprometem-se a adotar de maneira progressiva as medidas necessárias a fim de pôr em prática este direito e, especialmente, a: Proporcionar instalações adequadas, bem como alimentação e assistência médica especializada, às pessoas de idade avançada que careçam delas e não estejam em condições de provê-las por seus próprios meios [....]. (Protocolo de San Salvador, art. $17^{2}$ - grifos da autora).

\footnotetext{
${ }^{1}$ CENTRO INTERNACIONAL DE LONGEVIDADE. Declaração do Rio. Disponível em: < http://www.sbgg.org.br/ cms/wp-content/uploads/2013/11/RIO-DECLARATION-Portuguese-FINAL.pdf>. Acesso em: 31 maio 2014. ${ }^{2}$ CONVENÇÃO INTERAMERICANA DE DIREITOS HUMANOS. Protocolo Adicional à Convenção Americana sobre Direitos Humanos em Matéria de Direitos Econômicos, Sociais e Culturais, "Protocolo de San Salvador". Disponível em: <http://www.cidh.oas.org/basicos/portugues/e.Protocolo_de_San_Salvador.htm>. Acesso em: 31 maio 2014.
} 
Já a Carta de San José sobre os Direitos dos Idosos da América Latina e do Caribe de $2012^{3}$ detalha ainda mais o que seriam as ações de saúde para os idosos (incluindo a implementação da atenção preventiva com enfoque gerontológico e interdisciplinar, a oferta de serviços de reabilitação, o acesso a cuidados paliativos para a promoção de uma morte digna a pacientes terminais, a formação de cuidadores, entre outras ações). Embora não se trate de um texto com caráter normativo, oferece um bom indicativo do que poderia vir a ser integrado, idealmente, num tratado especial específico para os idosos, coisa ainda inexistente.

Assim, podemos imaginar que haverá, no plano internacional, uma evolução no sentido de se reconhecerem, expressamente, através de instrumentos normativos especiais, as especificidades do idoso, com a reafirmação do direito à saúde para esse grupo, que pode ser considerado como vulnerável. Tal caminho já foi percorrido pelo Direito Brasileiro, principalmente após a Constituição de 1988, e, hoje, a legislação de direitos dos idosos faz diversas referências ao direito à saúde. Mas se a saúde é um direito fundamental social, o autor do primeiro artigo aqui apresentado ainda questiona: trata-se de direito social absoluto? Argui, então, que pode haver restrições, desde que "proporcionais e constitucionalmente justificáveis". E segue afirmando que: "O conteúdo essencial de um direito fundamental social, atrelado ao princípio da dignidade humana, confunde-se com o mínimo existencial [...]". A dificuldade, como bem lembra o autor, está também em definir esse mínimo. Cita interessante decisão do Tribunal Constitucional Alemão de 2010, que menciona que o mínimo deve corresponder "ao nível de desenvolvimento da comunidade e das condições de vida existentes, sujeitos a atualização contínua [...]". O autor propõe então que, no caso da saúde, a judicialização das pretensões materiais de fornecimento se acompanhem ou sejam precedidos pela judicialização do direito procedimental, a fim de que se implemente a via administrativa para a obtenção do produto ou do serviço de saúde. Isso é necessário para evitar que as demandas materiais acabem sendo suportadas por outros recursos financeiros, sem relação com aqueles destinados à saúde, o que é fruto de desigualdade para os usuários. A reflexão proposta admite que, mesmo cumprindo-se as exigências procedimentais que possam ser impostas, o poder público ainda pode esbarrar na insuficiência de recursos, e propõe que os conflitos gerados em função disso podem ser examinados sob perspectivas distintas. O autor sustenta que, sob um ponto de vista teórico, a falta de recursos orçamentários não é um obstáculo para a exigibilidade e a justiciabilidade dos direitos aos cuidados de saúde. Mas que, na prática, a execução forçada de sentenças contra a administração pública também encontrará algumas limitações, relacionadas ao interesse público e ao não sacrifício de outros serviços essenciais. Defende, assim, pensar-se em um mínimo existencial em matéria de saúde, inclusive com relação ao idoso, trazendo diversas ilustrações.

${ }^{3}$ CEPAL. Carta de San José sobre os Direitos dos Idosos da América Latina e do Caribe. Disponível em: <http:// www.cepal.org/publicaciones/xml/0/48510/CartadeSanJosePortugues.pdf>. Acesso em: 31 maio 2014. 
O segundo artigo afirma o direito à saúde como um direito prioritário na velhice, com base no princípio do melhor interesse do idoso. Uma das relações que podem ser estabelecidas entre esse trabalho e o primeiro passa pela concepção proposta para o princípio do melhor interesse do idoso, segundo a qual este se apresenta como "comando de otimização" no sentido de que o melhor interesse se realiza na "maior medida possível, de acordo com as possibilidades jurídicas e fáticas". Quanto à saúde como direito prioritário, o artigo cuida da importância da saúde para a população idosa e sublinha a necessidade de efetivação desse direito para o gozo de outros direitos, como transporte, lazer e educação. É, sem dúvida, importante frisar a relevância da saúde para o gozo de outros direitos, mas cabe igualmente lembrar que a falta de acesso à educação ou ao trabalho, por exemplo, também vai afetar a saúde das pessoas: os direitos humanos são indivisíveis e interdependentes. A autora chega, enfim, a dar uma pincelada em uma questão que se relaciona com o terceiro artigo aqui proposto: como conciliar o respeito à autonomia do indivíduo e a sua proteção (no sentido de assisti-lo com atenção diferenciada, quando necessário)? Segundo a autora, encontrar esse fino equilíbrio também seria uma forma de se efetivar o princípio do melhor interesse do idoso.

O terceiro artigo se apresenta como significativa contribuição em termos de Direito Comparado, no caso, envolvendo o Direito Francês, para que reflitamos sobre o quadro existente e possíveis evoluções a serem pensadas para o Direito Brasileiro em matéria de informação do usuário de serviços da saúde e da assistência social e de expressão do consentimento e da vontade com relação a tratamentos ou cuidados de que a pessoa possa necessitar. Houve evolução recente no Brasil, com a Resolução do Conselho Federal de Medicina ${ }^{\circ}$ $1995 / 2012^{4}$, sobre as diretivas antecipadas de vontade dos pacientes. Contudo, ainda pairam inúmeras dúvidas sobre como essas disposições serão interpretadas em casos concretos pela jurisprudência. Faço coro aos que defendem que essa matéria deveria ser objeto de legislação específica. Outrossim, urge pensar-se, no Brasil, em uma reforma legislativa que integre a possibilidade de manifestação antecipada pela pessoa quanto à escolha de curador para si, em caso de interdição futura. Nos últimos anos, vários países, como a França, reformaram suas legislações nessa matéria, consagrando esse mecanismo. Assim, esse último artigo fecha o presente bloco temático com um assunto que, embora não se relacione exclusivamente com os direitos dos idosos, é de suma importância em uma sociedade que envelhece e com crescente população que enfrenta doenças crônicas, neurodegenerativas e incapacitantes.

${ }^{4}$ CONSELHO FEDERAL DE MEDICINA. Resolução no 1995, de 31 de agosto de 2012. Dispõe sobre as diretivas antecipadas de vontade dos pacientes. Disponivel em: <http://www.portalmedico.org.br/resolucoes/ CFM/2012/1995_2012.pdf>. Acesso em: 31 maio 2014. 
O direito à saúde, como direito humano universal, é o mesmo para todo ser humano. A implementação deste direito deve, contudo, atentar para as especificidades e necessidades de grupos vulneráveis, para que possamos concretizar o ideal de uma sociedade inclusiva para todas as idades.

\section{Referências}

CENTRO INTERNACIONAL DE LONGEVIDADE. Declaração do Rio. Disponível em: $<$ http://www.sbgg.org.br/cms/wp-content/uploads/2013/11/RIO-DECLARATIONPortuguese-FINAL.pdf $>$. Acesso em: 31 maio 2014.

CEPAL. Carta de San Josésobre os Direitos dos Idosos da América Latina e do Caribe. Disponível em: <http://www.cepal.org/publicaciones/xml/0/48510/CartadeSanJosePortugues.pdf >. Acesso em: 31 maio 2014.

CONSELHO FEDERAL DE MEDICINA. Resolução nº 1995, de 31 de agosto de 2012. Dispõe sobre as diretivas antecipadas de vontade dos pacientes. Disponível em: $<\mathrm{http} / / / \mathrm{www}$. portalmedico.org.br/resolucoes/CFM/2012/1995_2012.pdf>. Acesso em: 31 maio 2014.

CONVENÇÃO INTERAMERICANA DE DIREITOS HUMANOS. Protocolo Adicional à Convenção Americana sobre Direitos Humanos em Matéria de Direitos Econômicos, Sociais e Culturais, "Protocolo de San Salvador". Disponível em: <http://www.cidh.oas.org/basicos/ portugues/e.Protocolo_de_San_Salvador.htm>. Acesso em: 31 maio 2014.

Bibiana Graeff - Mestre em Direito Ambiental, Université Paris 1 - Panthéon-Sorbonne e Université Paris 2 - Panthéon-Assas; Doutora em Direito pela Université de Paris 1 - PanthéonSorbonne e Universidade Federal do Rio Grande do Sul. Professora adjunta da Escola de Artes, Ciências e Humanidades da Universidade de São Paulo. Vice-presidente do Instituto de Direito Comparado Brasil-França. São Paulo/SP, Brasil.E-mail: bibiana.graeff@usp.br. 